\title{
Ato, Conteúdo E OBJeto (Frege, Stout, Moore e a escola de Brentano)
}

\author{
MARio Ariel GonzÁlez Porta
}

\begin{abstract}
It is well known that the discussion concerning the relations between content and object is a central theme in Brentano's school after the decisive essay by Twardowski in 1894. However, less known is the fact that this discussion also takes place outside the aforementioned school and that the distinction between content and object is already present before 1893 amongst other authors.
\end{abstract}

Keywords: Frege; Stout; Moore; content-object.

\section{Introdução}

É bem sabido que a discussão sobre as relações entre ato, conteúdo e objeto constituí um momento chave no desenvolvimento da escola de Brentano a partir do ensaio de Twardowski de $1894 .{ }^{1}$ Contudo, esta discussão não se limita à escola de Brentano, mas é um tema central em muitos outros autores na ultima década do século. Ora, se a discussão das relações entre ato, conteúdo e objeto transcende a escola de Brentano, é por que ela, por sua vez, é meramente um aspecto de um contexto mais englobante, a saber, de uma renovação da teoria da subjetividade que se anuncia na segunda metade do século XIX, e que, girando em torno à oposição imanentismotranscendentalismo, questiona nas suas bases o legado moderno cartesiano-lockeano. Este interesse está presente nas mais variadas tendências (no neokantianismo, não menos que no pragmatismo, na escola de Brentano não menos que no positivismo empiriocriticista) e possui vários desenvolvimentos que se entrecruzam, tanto do ponto de vista estritamente sistemático, quanto do ponto de vista histórico-filosófico efetivo (Natorp-Twardowski, Mach-James, James-Natorp, Mach-Brentano, etc.).

Reconstruir este contexto em toda a sua dimensão é uma tarefa que ainda deve ser realizada e da qual, certamente, não podemos dar conta no presente texto. Nele, porém, daremos um primeiro passo nessa direção ao situar Frege e Moore no horizonte do referido movimento de renovação da teoria da subjetividade e, em especial, da polêmica em torno à distinção entre conteúdo e objeto. Com isto, nos propomos chamar a atenção tanto sobre o fato das relações de Frege e Moore com a escola de Brentano, quanto sobre o papel cumprido pela renovação da teoria da subjetividade nos primórdios da filosofia analítica.

Principia 19(1): 49-63 (2015).

Published by NEL — Epistemology and Logic Research Group, Federal University of Santa Catarina (UFSC), Brazil. 


\section{Frege}

\subsection{A evolução da crítica fregeana ao psicologismo}

Ainda que a crítica ao psicologismo seja uma constante no pensamento fregeano desde sua primeira até a sua última obra, a mesma experimenta importantes modificações através do tempo, que legitimam dizer que existe nela una evolução (González Porta, 2012). Para os efeitos do nosso interesse atual importa destacar as mudanças acontecidas entre 1884 e 1893, as quais podem ser resumidas em quatro pontos.

Em GGA ${ }^{2}$ Frege chega, através de um procedimento regressivo, a evidenciar o "idealismo" como origem última do psicologismo (1893, p.XXI). Isto é algo novo no seu pensamento, algo no qual há uma diferença decisiva entre a crítica ao psicologismo de GA e GGA. Em GGA Frege afirma explicitamente duas teses: por um lado, identifica o núcleo de donde surge o psicologismo na convicção de que nossos únicos objetos imediatos são nossas representações; por outro, contrapõe a esta tese a afirmação de que somos capazes de apreender diretamente objetos que não são representações. Em GA, por sua vez, Frege pressupõe que temos acesso a objetos que não são nossas representações $(1884, \S 93$, p.96). Disto se segue, indiretamente, que é falso que só temos acesso a objetos que são nossas representações. Isto não significa, porém, que ele considere que seja esta justamente a convicção que está na base do psicologismo e o motiva, tese esta que é o eixo do argumento regressivo de GGA.

O problema do psicologismo era concebido em GA como um problema essencialmente referido a objetos ideais e derivado justamente da natureza ideal destes objetos. Correlativamente, o psicologista que Frege critica nesta obra, concede sem questionar a existência de objetos reais não menos que o nosso acesso aos mesmos. Algo diferente ocorre em GGA: o psicologista não só nega a existência de objetos ideais, mas também questiona o nosso acesso direto a objetos reais, e, em última instância, o faz nos dois casos pelo mesmo motivo (1893, p.XXIII). O psicologista de GA é, em última instância, um empirista que afirma irrestritamente os direitos do conhecimento sensível, negando toda pretensão epistemológica que vai além dele (1884, §26-27, p.39-42). Todavia, se o psicologismo deriva em GA do empirismo, em GGA provém do idealismo (1893, p.XXI).

A diferença entre GA e GGA não é puramente quantitativa, de modo tal que na segunda se considera a psicologização de mais objetos que na primeira, ou seja, que o psicologismo dos objetos ideais da primeira é agora estendido aos reais. O que mudou de GA a GGA é o diagnóstico de qual seja a origem última do psicologismo e, correlativamente, a definição de em que consiste propriamente este. Tanto em GA como em GGA o psicologista subjetiva estruturas ideais. No entanto, se o resultado é em ambos os casos o mesmo, o motivo que conduz a tal subjetivização (e, em consequência, o alcance do psicologismo) é diferente. Em GA, o número e o ideal

Principia 19(1): 49-63 (2015). 
em geral se reduzem a representações porque não se admite a existência do objetivo não-real (1884, §26, p.39-41); em GGA, porque, além do anterior, as representações são nossos únicos objetos (1893, p.XX, XXII, XXIV-XXV).

Não só há uma mudança de GA a GGA, mas também há um aprofundamento da própria posição e da compreensão da sua diferença com a oponente. A admissão da existência do objetivo não-real é em GA a última palavra, sendo que em segundo plano permanece o fato de que somos capazes de o captar. Em GGA, pelo contrário, fica claro que a distinção entre o objetivo e o real não coloca um ponto final na discussão, mas é meramente um momento provisório, ponto de passagem para um desenvolvimento ulterior que haverá de conduzir a algo ainda mais essencial (1893, p.XVIII).

Enquanto que em GA o psicologismo tende a ser visto como um problema referido a um reducionismo do objeto, em GGA o mesmo é visto como um problema derivado de uma falsa concepção do sujeito. O psicologismo é em GA a consequência de uma negação da existência de certos objetos, os ideais e, em tal sentido, uma tese “ontológica”, referente a que objetos há. Em GGA, pelo contrário, o psicologismo é primariamente uma consequência de uma falsa concepção da subjetividade.

Esta falsa concepção da subjetividade gira em torno à crença no "princípio de imanência" (PI). Entenderei por PI a tese cartesiano-lockeana de que os únicos objetos diretos e imediatos da minha consciência são as minhas próprias ideias ou representações. Em princípio, corretamente entendido, o que Frege chama "idealismo" e, mais precisamente, "idealismo epistemológico" (1897, p.62) não é outra coisa que o que acabo de chamar PI. Se, apesar do anterior, eu introduzi esta expressão, é por que não é incomum na critica que se fixe inadequadamente o conceito fregeano de "idealismo". Seja observado, pois será decisivo no que segue, que a negação do PI supõe distinguir de algum modo entre conteúdo e objeto no sentido de Twardowski, embora que, como o evidencia Höffler, a distinção entre conteúdo e objeto não necessariamente supõe a negação do PI e, em consequência, a superação de todo "representacionalismo".

\subsection{As "influências" externas: a polêmica com Kerry}

Se a análise anterior é correta, e é certo que houve uma evolução significativa na critica fregeana ao psicologismo entre 1884 e 1893, então a pergunta que se impõe é se a mesma se deveu a um desenvolvimento puramente imanente do pensamento fregeano ou se nela jogam algum papel influências externas. Esta última opção parece ser a correta. Frege recebeu sete resenhas aos seus "Fundamentos da Aritmética", das quais três se manifestam sobre o tema do anti-psicologismo de modo positivo (Lasswitz, Cantor e Eucken), três, sem embargo, são criticas neste ponto (Hoppe, Husserl e Kerry). A crítica de Hoppe não passou de uma contraposição dogmática de pontos 
de vista incomensuráveis; as de Kerry, pelo contrário, são filosoficamente substanciais e merecem uma consideração especial, mesmo por que elas são imprescindíveis para fixar o horizonte adequado tanto para entender a crítica de Husserl a Frege, quanto a reação deste às mesmas.

\subsection{As criticas de Kerry a Frege e a legitimidade da luta antipsciologista}

Kerry dirige quatro críticas a Frege:

a. A primeira é bem conhecida e diz respeito à diferença entre conceito e objeto. É de se ter em conta, no entanto, que ela é uma consequência da oposição entre abordagem psicológica e lógica.

b. A segunda aponta ao fato de que Frege trabalha com um conceito de lógica que não determina de modo adequado (1887, IV, p.261).

c. A terceira denuncia que Frege apela sem mais à "Razão" como faculdade de apreensão do objetivo não-real (1884, §26-27, p.41-42), o qual não representa outra coisa que um "hipostasiar uma faculdade totalmente inarticulada (ungegliedert) como fundamento da objetividade", algo que não acompanha a situação da pesquisa psicológica da época (1887, IV, p.305-307).

d. A anterior objeção é meramente um aspecto de uma outra, mais abrangente, a quarta, que estabelece uma recusa de princípio do combate antipsicologista fregeano (1887, IV, p.305). É nela que devemos nos concentrar.

Kerry dirige quatro substanciais críticas ao antipsicologismo fregeano:

a. Uma fundamentação psicológica da lógica/matemática não implica necessariamente uma ameaça à objetividade das mesmas ou o perigo do subjetivismo.

b. Se o anterior é correto, se segue que o radical combate de Frege ao psicologismo é infundado. Logo, Frege alerta contra um perigo que não existe. Por tal razão, seu antipsicologismo radical deve sem mais ser ironicamente desqualificado como "horror subjectivi".

c. Mas se, segundo a opinião de Kerry, Frege, com sua rigorosa divisão entre lógica e psicologia, vê, por um lado, um problema que de fato não existe, por outro, não vê a verdadeira dificuldade que resulta inevitável neste contexto, a saber, o como pode surgir validade objetiva a partir do subjetivo. Com isto, Kerry não exige de Frege meramente uma "complementação" de sua posição, uma complementação que Frege poderia talvez fornecer, se a isto se propusesse. Pelo contrário, Kerry quer apontar para uma dificuldade de princípio na tese de seu oponente, uma dificuldade que ele só poderia superar se abandonasse seu ponto de partida. Dado que Frege, e em que pese todo seu "objetivismo", não pode evitar responder a pergunta pela apreensão do objetivo, esta

Principia 19(1): 49-63 (2015). 
o deveria levar então à negação de sua tese de que se deve separar do modo mais radical possível o objetivo e o subjetivo ou, dito de outro modo, que se deve fundamentar a objetividade da matemática sem qualquer consideração psicológica.

d. Certamente que, para um leitor desprevenido, não é em princípio evidente, que a linha de pensamento de Kerry seja em modo algum conclusiva. Para que se torne tal, deve-se atentar ao final da frase: “... do qual de qualquer forma toma seu início nosso conhecimento...". Kerry argumenta que, ainda que se separe psicologia e lógica e se sublinhe o objetivo tanto quanto se quer, em ultima instância, não obstante, o subjetivo não se deixa eliminar, dado que todo conhecer necessariamente parte de um sujeito. Nós devemos explicitar o sentido desta premissa. Para isto notemos, em primeiro lugar, que a oposição subjetivo-objetivo é equivalente à oposição imanente-transcendente. Se formularmos agora a tese de Kerry com base nesta última oposição, torna-se então mais claro o que, em última instância, está em jogo, quer dizer, o PI.

O argumento de Kerry reza:

a. Nossos únicos objetos imediatos são os conteúdos de nossa consciência, ou seja, nossas representações.

b. Por isto, a única transcendência sobre a qual pode-se com sentido falar é a que pode ser alcançada a partir da imanência.

c. Portanto, se se quer falar sobre a transcendência, deve-se primeiramente explicar como ela é dada a partir da imanência.

d. Isto, sem dúvida, é impossível sem o recurso ao método psicológico.

e. Em consequência, a mera insistência radical na separação de transcendência e imanência, lógica e psicologia, passa por alto o verdadeiro problema.

\subsection{A reação de Frege à critica de Kerry}

Uma vez mostrado que a crítica de Frege ao psicologismo enfrentou reações, colocase inevitavelmente a pergunta de em que medida ele as tomou em consideração, ou seja, se impõe então a pergunta se Frege respondeu especificamente a este ponto da crítica de Kerry. A este respeito, deve-se observar que Frege nunca se refere a tal crítica de modo expresso, porém talvez implícito. Sem ser mencionado, Kerry parece ser onipresente no prefácio de GGA, não menos que em num importante trecho da "Lógica" de 1897.

O objetivo de Frege em GGA é expressamente clarificar seu conceito de lógica por contraposição à concepção rival, isto é, à psicologista (1893, p.XXV). Mas por que 
Frege considera necessário isto justamente agora? Possivelmente, para responder à crítica de Kerry, segundo a qual, ele não possui um conceito claro de lógica.

O fato de que Frege se propunha a fazer no prefácio de GGA uma clarificação da disputa é totalmente coerente com o já indicado procedimento regressivo do texto. Ora, se vamos além de considerações sistemáticas, é explícito no texto que Frege está interessado em chegar à verdadeira "origem da discussão" (1893, p.XVIII), ao ponto no qual, em definitivo, toda a questão "desemboca" (1893, p.XIX). Quer dizer, Frege é explícito na sua intenção de colocar um ponto final na discussão com o psicologismo, sendo que este ponto final, como vimos, não é outro que o identificar o idealismo como a verdadeiro origem do psicologismo, ou seja, a manutenção do PI como suposto inconfessado e inquestionado em que se baseia toda a critica de Kerry.

Se, por um lado, Frege procede regressivamente ao estabelecer a fonte última da diferença entre sua posição e a de seus opositores, por outro, ele dá muita importância a ressaltar que a última consequência do idealismo é o relativismo. Isto pode parecer estranho para um leitor atual. De fato, à primeira vista se pensaria que um idealista no sentido fregeano necessariamente seria um relativista. Entretanto, isto não era algo que todo defensor do método psicológico concederia sem mais, começando pelo próprio Brentano, mas continuando por Kerry. Por isso, é um objetivo principal do texto tornar evidente que o relativismo é uma consequência inevitável da aceitação do PI (1893, p.XVIII, XIX, XX, XXI, XXII).

Uma vez que Frege, pela via sistemática e através de uma reconstrução puramente lógico-conceitual, chega à conclusão que o idealismo encontra-se na base do psicologismo, muda seu objetivo e, com isto, também seu modus operandi. Ele procura então tornar evidente que a linha de pensamento descrita não é somente a que está na base do psicologismo de um ponto de vista puramente lógico, como também aquela na qual de fato ele se funda. É justamente por isso que Frege toma Erdmann como alvo e o cita pormenorizadamente. Se agora nos perguntamos, por que para Frege é tão importante provar, por meio de generosas citações, que Erdmann efetivamente procede como ele descreve, não necessitamos especular muito acerca da resposta, pois esta é fornecida expressamente por Frege: ele quer mostrar que não luta contra "moinhos-de-vento" (Windmühlen), e sim que o perigo, ao qual ele se refere, é um perigo real (1893, p.XIX). Tal proceder faz todo sentido se se considera que seu pano de fundo é a já mencionada ironia de Kerry que Frege padece de um "horror subjectivi".

Na "Lógica" de 1897 há um trecho famoso, que há muito é citado como prova irrefutável de que Frege não possui nenhum interesse por questões referentes à subjetividade, já que ele remete sem mais o tema da apreensão do pensamento (Gedanke) à psicologia. $\mathrm{O}$ trecho mencionado diz sem dúvida isto, mas não só isto. Tirado de seu contexto, instiga uma impressão falsa e parcial. Ele é muito mais complicado do que à primeira vista pareceria e contêm vários outros elementos, que em geral 
são passados por alto. No percurso anterior do texto Frege defendeu a tese de que pensamentos não podem ser entidades psíquicas, isto é, não podem ser nem representações, nem conexões de representações. Frege se coloca então uma objeção: se pensamentos não podem ser psíquicos, ao menos se deve admitir que a apreensão dos pensamentos seja um "processo anímico" (seelischer Vorgang) (1897, p.63-64). Em primeiro lugar, deve-se insistir que, sob uma perspectiva puramente formal, jaz aqui uma séria objeção à posição de Frege, um argumento consistente em referir-se a uma suposta verdade inegável que contradiz o ponto de partida de todo o raciocínio fregeano. Contudo, não é tão simples de se compreender por que é assim. Em princípio, poder-se-ia pensar que não há necessariamente uma contradição entre o fato de que pensamentos não sejam psíquicos e que sua apreensão o seja, e que todos, inclusive Frege, devem admitir que a apreensão do pensamento é um processo anímico. Se, todavia, a passagem mencionada deve conter um argumento, é por que se pensa que o fato de que a apreensão do pensamento seja algo psíquico, implica que também o apreendido o deva ser. O que é pressuposto, é, pois: o apreender é algo psíquico, e algo não pode ser apreendido, sem igualmente ser ele mesmo algo psíquico. Mas isto não é uma evidência em si. Torna-se evidente, não obstante, se formos mais adiante e aceitarmos que o sujeito só pode apreender o que existe "nele", isto é, se pressupomos a validade do PI. Ora, se a objeção que Frege considera na "Lógica" de 1897 é colocada desta forma, resulta claro que ela está intimamente relacionada com aquela que Kerry lhe dirige uma década antes.

Sendo a objeção que Frege se coloca no texto de 1897 basicamente a mesma que Kerry lhe colocara, resulta então ainda mais crucial atentar para o modo como Frege reage à mesma na continuação do texto. Com efeito, Frege observa que, mesmo que o processo em questão seja psíquico, ele se encontra no limite do psíquico e, isto, porque ali introduz-se um elemento, o pensamento, que não é nada psíquico. À primeira vista poderia parecer que Frege não oferece resposta à objeção, mas somente uma asserção tão dogmática quanto a de seu oponente: enquanto este afirma que a apreensão do pensamento é algo psíquico, Frege simplesmente nega que este seja o caso. Esta impressão, porém, é falsa. Com certeza, Frege não quer (nem pode) negar que a apreensão do pensamento seja um processo psíquico. O que ele nega é o fato de que, por que o processo é psíquico, o apreendido também deva sê-lo. O ponto decisivo aqui é que não por que o pensamento seja apreendido, ele deve tornar-se psíquico. Por conseguinte, a resposta de Frege consiste em clarificar a pressuposição do opositor em seu caráter de tal para, na continuação, negá-la.

Mas Frege não meramente se coloca uma objeção similar à de Kerry e a responde, mas, na sua resposta, reformula ao mesmo tempo o problema. O problema não pode ser o como o objetivo surge do subjetivo, como pretendia Kerry, e sim o como o sujeito psicológico capta algo que não é o seu conteúdo imanente. Corretamente formulado, o problema não consiste em como o pensamento se produz (hervorbringen), senão 
em como se o apreende (fassen) (1897, p.37), ou seja, em como se apreende algo transcendente, que não por ser apreendido, se torna imanente, senão que permanece tão transcendente quanto o é em si. Este problema, nos diz Frege, não tem sido compreendido na sua verdadeira dificuldade pela psicologia de seu tempo, porque esta, enquanto tenta derivar o pensar das representações, aceita sem mais que estas são nossos únicos objetos (1897, p.64n).

Entretanto, se este problema não tem sido compreendido na sua verdadeira dificuldade, o problema de Kerry respeito da origem do objetivo a partir do subjetivo, é um problema mal colocado, cuja solução, no melhor dos casos, de fato clarifica unicamente à questão de como surge a aparência de objetividade (1897, p.62). Frege está, pois, corrigindo a própria pergunta de Kerry e recolocando-a do modo correto.

\section{Stout e a Escola de Brentano: Contéudo e Objeto}

Se todo o anterior é certo, então se segue que em 1893, isto é, um ano antes de Twardowski, Frege, com sua critica ao PI, está apontando a necessidade de distinguir entre conteúdo e objeto. Todavia, Frege não é o único que neste ano dá um passo decisivo no sentido da distinção indicada.

No seu ensaio "A filosofia de Mr. Shadworth Hodgson", Stout chama a atenção sobre o fato de que este autor simplesmente pressupõe que o objeto ao qual a consciência se refere é sempre eo ipso um estado da própria consciência (1892, p.109), e lhe contrapõe a tese de que o objeto da consciência jamais pode ser una mera modificação da mesma no momento em que a consciência se dirige a ele (1892, p.110 e 111), pois isto implicaria o absurdo de identificar a existência de uma ideia com a existência daquilo de que ela é ideia.

O próximo passo de Stout será agora uma distinção explícita entre conteúdo e objeto em base ao fato de que enquanto o conteúdo é real na consciência, o objeto não é real nela. Stout elabora a distinção mencionada sobre a base de uma análise de três modos de consciência diferentes:

a. Quando eu percebo uma árvore, eu certamente tenho na minha consciência um certo complexo de elementos visuais, tácteis e motores que consistem em parte de sensações atuais e em parte de resíduos re-vivenciados de anteriores sensações. O ponto é, porém, que estas experiências não são o objeto da minha consciência. Este objeto não é outro que a árvore, considerada como existindo e persistindo independente de mim e da minha percepção (1892, p.111).

b. Quando eu desejo algo, o objeto do meu desejo não pode ser um conteúdo imediato de consciência, porque este, enquanto existente nela, não cumpre com a condição necessária para poder ser desejado (1892, p.112). 
c. O problema da referência a um objeto que não é parte da consciência, não é remitido por Stout meramente a objetos do mundo externo, senão inclusive a objetos da própria consciência, como, por exemplo, uma sensação. Ora, se neste caso tampouco é possível para o objeto da consciência estar presente nela quando o sujeito o pensa, logo resulta de principio óbvio que em nenhum caso o pode ser (1892, p.112).

Estabelecida a crítica, Stout passa a delinear a sua própria análise positiva da consciência. O processo de se tornar consciente de um objeto consta de três elementos:

a. um pensamento de ... (thought) ou referência a algo (thought reference) que, ainda que intencionado pela consciência, não é uma modificação presente nela;

b. um conteúdo de consciência ou "apresentação" (presentation) que é real na consciência e determina a direção do pensamento a um objeto específico;

c. a atenção, concebida como atividade espontânea do sujeito, que é a função que confere à mera apresentação referência a um objeto.

A apresentação junto com a referência é o que chamamos "ideia" (1892, p.112113). A apresentação, pois, deve ser distinguida da ideia, distinção que pretende dar conta de que, no seu sentido usual, o termo "ideia" não nomeia unicamente a apresentação, mas propriamente o composto de apresentação e referência.

O status da apresentação exige uma atenção peculiar. A noção de apresentação foi introduzida para dar conta de uma parte de um todo que é a ideia e, portanto, como vinculada a uma relação intencional. A pergunta é, não obstante, se também podemos ter apresentações independentemente desta relação. A resposta é afirmativa. Existe uma relativa independência das apresentações com respeito a toda referência ao objeto. Ela se exemplifica de três formas:

a. sensações orgânicas, como se sentir bem ou mal;

b. sensações que numa percepção dada não caem sob a atenção e, portanto, não recebam um significado;

c. processos de generalização, nos quais a partir de um conteúdo atual absolutamente concreto, se desconsideram aspectos do mesmo para pensar uma significação universal como o verdadeiro objeto.

As apresentações consideradas como tendo existência independente do pensamento são chamadas "sentiencia" (sentience) ou "consciência anoética". Pensamento e sentencia são, pois, duas funções mentais essencialmente distintas e reciprocamente irredutíveis (1892, p.116-117). É possível que existam seres que só possuam consciência anoética, mas isto não se pode afirmar com certeza. 
Numa sentiencia todo o seu ser consiste no seu ser percebido. Este ser percebido, contudo, não pode ser confundido com qualquer tipo de relação sujeito — objeto. A única relação possível entre duas instâncias de sentiencia ou entre uma sentiencia e a consciência como um todo, é a de todo e parte (1892, p.116).

Em 1896, na sua "Descriptive Psychologie" Stout volta sobre o tema, sendo que neste momento ele já há lido Twardowski e recebido a sua influência. Correlato do anterior, é que a distinção entre conteúdo e objeto se efetua agora no marco de uma crítica explícita a Brentano, quem é interpretado no mesmo sentido que o fizeram seus discípulos germânicos (1896, p.41). Produto da influência de Twardowski, é que em 1896 Stout faz especial referência à questão dos objetos não-existentes ao introduzir a distinção objeto-conteúdo.

Não obstante o anterior, existem três importantes diferenças entra a sua posição e a de Twardowski.

Os argumentos nos quais Stout baseia a sua distinção conteúdo objeto são três:

- O objeto de um ato pode não existir enquanto que todo ato têm um conteúdo.

- O objeto pode ter propriedades que não são propriedades do conteúdo.

- O conteúdo pode cambiar, enquanto que o objeto permanece o mesmo e viceversa.

Como se vê, se os dois primeiros argumentos têm um perfeito correlato em Twardowski, não assim o terceiro, e devido à sua segunda parte ("e vice-versa"). Esta diferença está intimamente vinculada ao fato de que Stout orienta a introdução da distinção conteúdo-objeto basicamente ao ato perceptivo. Com respeito a este (mais concretamente, à apreciação da relação entre tamanho real e aparente dos objetos, que é o exemplo predileto de Stout), a sua observação faz sentido.

Será justamente o fato de que a noção de conteúdo surgiu referida à percepção, o que produzirá uma segunda diferença entre Stout e Twardowski na teoria da significação e do juízo. Contra Twardowski, Stout nega que o conteúdo do juízo seja o significado, dado que o conteúdo como tal é meramente psíquico e privado; a significação, pelo contrário, algo não-psíquico e público. A significação de um termo e o correlato de um juízo, pois, não é outro que o próprio objeto.

Se a distinção entre conteúdo e objeto, como vimos, não implica por si mesma a negação do PI, ela tampouco implica necessariamente a opção pelo realismo no conflito realismo-idealismo. Em tal sentido são importantes dois pontos:

1. Sublinhar a independência do objeto com respeito à consciência não implica para Stout aceitar a existência de uma coisa em si, ideia esta que ele rechaça expressamente como absurda. Coerente com seu interesse primariamente psicológico, Stout considera que a distinção entre conteúdo e objeto é neutral

Principia 19(1): 49-63 (2015). 
desde o ponto de vista metafísico (1896, p.45-46) e conciliável com o idealismo e, inclusive, com o solipsismo (1896, p.46). Uma teoria como a milleana da identidade do objeto perceptivo com a possibilidade da sensação, sendo inequivocamente idealista, respeita, segundo Stout, a distinção conteúdo-objeto (1896, p.43).

2. Mas Stout vai além e, explicitamente, afirma que a tese de que existe uma diferença entre o conteúdo e o objeto vale unicamente de modo irrestrito para uma consciência finita, mas não para uma consciência infinita, como a pensada por Hegel. Em relação a esta, e justamente pelo seu caráter de infinita, se pode dizer com pleno direito que todos os objetos estão nela (1896, p.45). O inimigo de Stout não é, pois, o idealismo enquanto tal, mas propriamente o idealismo subjetivo.

\section{Moore e "A Refutação do Idealismo"}

As precisões anteriores são necessárias para situar corretamente a Moore no contexto que nos ocupa. Moore retoma de Stout a distinção entre ato e objeto. Porém, esta distinção será liberada por Moore de todo compromisso com o idealismo para servir de base à defesa de um radical realismo direto.

O idealismo é a tese de que todo ser é espiritual (1903, p.433). Ora, "A refutação do idealismo", não contém uma refutação desta tese, mas só de um pressuposto necessário de todo argumento a favor da mesma (1903, p. 436). Este pressuposto é o "esse est percipi" berkelyano, que, não sendo em si mesmo evidente, se funda, em última instância, na pretendida evidência da tese "que o objeto de experiência não pode ser concebido aparte do sujeito" (1903, p.441). Esta tese vai se apresentar em três variantes, que tem um grau de generalidade decrescente e inversamente proporcional a sua evidencia, como relação sujeito-objeto, experiência-experimentado, azul e sensação de azul (1903, p.441, 442, 443, 445, 448).

Em esquema, a refutação desta tese se efetua por três procedimentos, ora mostrando

a. que ela é contraditória (1903, p.441ss.),

a.1. seja porque identifica duas coisas diferentes (p.441-2);

a.2. seja por que ainda distinguindo-as, as considera inseparáveis (p.442ss.);

b. ou evidenciando de modo introspetivo-fenomenológico que, de fato, ela é falsa (p.443ss.),

b.1. seja estabelecendo para isso a análise correta de uma ideia (p.444ss.);

b.2. seja denunciando a análise falsa (p.447ss.);

Principia 19(1): 49-63 (2015). 
c. ou evidenciando que dela se seguem consequências absurdas (p.451).

Ora, o ponto decisivo é que tanto a refutação por contradição quanto a refutação por consequências pressupõem em última instância a refutação introspectivofenomenológica por falsidade (1903, p.450).

Se vamos além das aparências motivadas pela literalidade do texto, o verdadeiro "argumento" de Moore não é outro que um procedimento regressivo que busca em primeira instância explicitar o pressuposto último no qual se assenta o idealismo. Este pressuposto não é outro que a convicção de que é intuitivamente evidente que o objeto da consciência está nela (1901-1902, p.157 e 1903, p.453).

A identificação deste suposto é correlativa à proposta de uma nova ideia de subjetividade que, ainda que possa ser empregada como base de uma refutação do idealismo, pois é simplesmente a outra face da mesma, é em si mesma autônoma e auto-suficiente.

Se compararmos nossa sensação de azul com outra de amarelo, observamos que há entre elas algo em comum e algo diferente. $\mathrm{O}$ algo em comum (entre si, e com qualquer outra sensação que possamos pensar é justamente o que chamamos "consciência"; o algo diferente, é o "objeto" ao qual a consciência se dirige. Entre a consciência e seu objeto existe uma relação sui generis, absolutamente irredutível a toda outra e que podemos chamar relação de "knowing of", em que o "of" não pode ser eliminado sem que por isto se elimine a peculiaridade de tal relação. A sensação é sempre sensação de algo e esse algo é o seu objeto. Dito de outro modo: a relação da consciência a seu objeto não pode ser reduzida a uma relação de todo e parte. $\mathrm{O}$ objeto da consciência não é jamais o seu conteúdo. Mais ainda, não existe propriamente algo assim como um conteúdo, seja como mediação ao objeto, seja como mera sentiencia. Ora, é da natureza dessa relação, não só que o objeto seja algo diferente da consciência, mas absolutamente transcendente a ela (1903, p.453) e que o objeto de toda consciência seja evidente no mesmo grau e pela mesma razão (1903, p.453). Em consequência, não há nenhuma diferença entre a consciência de azul e a de um objeto do mundo exterior. Ambos são igualmente transcendentes e igualmente dados de modo direto e imediato à consciência (1903, p. 451). Uma correta descrição da consciência elimina o problema da saída ao mundo externo, já que ser consciente é eo ipso captar algo transcendente à consciência.

A consequência da tese de Moore é não só que a consciência pode captar algo transcendente a ela, mas que só pode captar algo transcendente a ela. Mais ainda, não se trata meramente de descrever corretamente a relação na qual a consciência entra com o seu objeto no conhecimento, mas a única forma na qual isso, chamado consciência, pode existir. A relação da consciência a seus objetos, pela sua própria natureza, e independentemente de seus objetos, é sempre a mesma. 


\section{Conclusão}

Para concluir, comparemos por um lado Frege, Stout e Moore entre si, e, por outro, todos eles com a escola de Brentano, individual e coletivamente.

Que há importantes coincidências nos princípios que orientam suas filosofias entre Frege e Moore é evidente: ambos são realistas, radicais objetivistas e lutam com igual decisão contra todo subjetivismo e relativismo sobre a base de certo platonismo. Ora, no ponto que nos ocupa, as diferenças entre Frege e Moore são à primeira vista muito maiores do que resultam quando se as submete a uma análise mais detida. Com efeito, os objetivos de ambos são claramente diferentes, pois Frege se propõe combater um idealismo epistemológico, próprio do naturalismo alemão do fim do século, Moore um ontológico, próprio de idealismo neo-hegeliano inglês. Porém, as distâncias se encurtam decisivamente pelo fato de que Moore não considera possível refutar o idealismo ontológico, mas só uma dessas premissas. Assim, em que pese à aparência de total diversidade que os modos de argumentação apresentam numa primeira olhada, em ambos joga papel essencial um procedimento regressivo que busca explicitar o suposto último do oponente e evidenciar que é errôneo. Mais ainda, o procedimento regressivo chega em ambos casos à mesma conclusão. O que Frege considera como suposto de todo psicologismo e Moore de todo idealismo é em definitivo o mesmo, a saber, o PI. Tanto para Moore, quanto para Frege, o objeto da consciência não pode ser confundido com o seu conteúdo, seja que o conteúdo exista (Frege), ou não (Moore).

Em suma, ambos consideram que na base do idealismo se encontra uma falsa doutrina da subjetividade e, por isso, as suas críticas do idealismo são uma crítica de certa teoria da subjetividade. Mas, ainda tendo importantes pontos em comum, as duas concepções de subjetividade de Frege e Moore possuem também importantes diferenças e, em definitivo, permanecem reciprocamente irredutíveis. Frege defende uma concepção ato-conteúdo-objeto da consciência que aceita tanto a existência do conteúdo real (que pode se dar só ou como meio de relação ao objeto), quanto à necessidade de um conteúdo ideal. Moore, por sua vez, defende uma concepção atoconteúdo da consciência na qual não só o conteúdo não é objeto da consciência, mas não há conteúdo e, portanto, nem sentiencia, nem mediação sensível ao objeto, como em Stout. Isto não implica, porém, que Frege, tanto quanto Moore, não aceite uma relação direta a certos objetos, a saber, os Gedanke, que, enquanto objetos, são apreendidos de modo tão direto quanto os concepts de Moore.

Estas diferenças gerais entre Frege e Moore na teoria da subjetividade se concretizam pontualmente na teoria da percepção, não menos que na teoria da significação e do juízo. Moore, como Stout, e por conceber como este todo conteúdo como meramente psicológico, tem uma teoria puramente referencial do significado na qual não há lugar para entidades intencionais mediadoras, como os "Gedanke" fregeanos. As

Principia 19(1): 49-63 (2015). 
dificuldades recíprocas de compreensão entre Frege e Russell a respeito do lugar que ocupa o Monte Blanco nas proposições que o tem por objeto, serão uma decorrência destas diferenças e, em consequência, a polémica semântica de ambos, ao menos em parte, uma derivação de divergências teórico-subjetivas.

Em suma, existe uma discussão sobre as relações entre conteúdo e objeto fora da escola de Brentano que, por um lado, em parte é independente dela, e em parte interage com ela de modos diversos, e, por outro, desenvolve variantes que são correlatas com aquelas desenvolvidas na escola de Brentano, e em parte não. A posição de Moore tende a coincidir com a de Meinong, a de Frege, com a de Husserl, a de Stout, que tem um componente idealista atípico na escola de Brentano e, justamente por esse motivo, fica presa ao que pretende superar tanto como a de Höffler, ainda que não num contexto realista como este. Mas o fato de que a relação entre ato, conteúdo e objeto seja um tema presente além da escola de Brentano, é meramente uma consequência do fato de que existe um amplo movimento de renovação da concepção moderna de subjetividade, devendo-se entender a escola de Brentano e a ulterior fenomenologia como mas uma opção nesse contexto.

\section{Referências}

Banks, E. C. 2014. The realistic empiricism of Mach, James, and Russell. Neutral Monism Reconceived. Cambridge: Cambridge University Press.

Betti, A. 2013. We owe it to Sigwart! A new Look at the content/object distinction in early Phenomenological Theories of Judgment from Brentano to Twardowski. In: M. Textor (ed.) Judgment and Truth in early analytic philosophy and phenomenology, p.74-96, New York: Palgrave Macmillan.

Erdmann, B. 1892. Logik. Logische Elementarlehre. Halle: Niemeyer.

Frege, G. 1971 [1879]. Begriffsschrift. Eine der arithmetischen nachgebildeten Formelsprache des reinen Denkens. In: Begriffsschrift und andere Aufsätze. 2da. ed. Ignacio Angelelli (ed.), p.1-88, Darmstadt: Wissenschaftliche Buchgesellschaft.

— 1988 [1884]. Die Grundlagen der Arithmetik. Eine logisch mathematische Untersuchung über den Begriff der Zahl. Hamburg: Meiner. (GA)

- 1893. Grundgesetze der Arithmetik. Jena: Pohl. (GGA)

- 1980 [1897]. Logik (1897). In: G. Gabriel (org.) Schriften zur Logik und Sprachphilosophie. Aus dem Nachlass. 3.Aufl. Hamburg: Meiner.

—. 1986 [1918]. Der Gedanke. In: G. Frege. Logische Untersuchungen. Göttingen: Vandenhoeck und Ruprecht.

- 1894. Besprechung Husserl's Philosophie der Arithmetik. Zeitschrift für Philosophie und philosophische Kritik NF 103: 313-332.

—. 1966 [1892]. Begriff und Gegenstand, In: G. Patzig (org.) Funktion, Begriff, Bedeutung. Gottingen: Vandenhoeck und Ruprecht.

González Porta, M. A. 2009. A crítica de Frege ao idealismo en 'Der Gedanke'. Veritas 54: 130-54.

Principia 19(1): 49-63 (2015). 
- 2012. La evolución de la crítica fregueana al psicologismo. Veritas 57: 99-122.

- 2014. Freges Logik von 1897 und die Subjektfrage. Phainomenon 22-23: 31-66.

- 2014. Crítica al psicologismo y concepción de subjetividad en Frege. Manuscrito 37: $1-57$.

Hoppe, E. R. E. 1885. Rezension der Grundlagen der Arithmetik. Archiv der Mathematik und Physik. 2.Reihe. Teil II, Heft III: 28-35.

Husserl, E. 1992 [1891]. Philosophie der Arithmetik. Hamburg: Meiner.

Kerry, B. 1887. Über Anschauung und ihre psychische Verarbeitung. Vierter Artikel. Vierteljahresschrift für wissenschaftliche Philosophie 11: 249-307.

Moore, G. E. 1901-1902. Mr. Mc Taggart's "Studies in Hegelian Cosmology". Proceedings of the Aristotelian Society 2: 177-214.

- 1903. The refutation of idealism. Mind 48: 433-53.

- 1922. Philosophical Studies. London: Kegan Paul, Trench Trubner.

- 1986. The Early Essays. Tom Regan (ed.). Philadelphia: Temple University Press.

- 2013. Selected Writings. Thomas Baldwin (ed.). 1a. ed. 1993. London/New York: Routledge.

Nasim, O. W. 2008. Bertrand Russell and the Edwardian Philosophers. Constructing the World. New York: Palgrave Macmillan.

Preti, C. 2008. On the origins of the contemporary notion of propositional content: antipsychologism in nineteenth century psychology and G. E. Moore's early theory of judgment. Stud. Hist. Phil. Sci., doi 10.1016/j.shpsa.20089.03.002.

Peckhaus, V. 1994. Benno Kerry. Beiträge zu seiner Biographie. History and Philosophie of Logik 15: 1-8.

Picardi, E. 1994. Kerry und Frege über Begriff und Gegenstand. History and Philosophy of Logik 15: 9-32.

Rollinger R. D. 2009. Brentano's Psychology and Logic and the Basis of Twardowski's Theory of presentations. The Baltic International Yearbook of Cognition, Logic and Communication 4: 1-23.

Stout, G. F. 1892. The Philosophy of Mr. Shadworth Hodgson. Proceedings of the Aristotelian Society 2: 107-20.

- 2012 [1896]. Analytic Psychology. London: George Allen \& Unwin Ltd. / New York: The Macmillan Company (Forgotten Books).

Van der Schaar, M. 2013. G. F. Stout and the psychological origins of analytic philosophy. New York: Palgrave Macmillan.

MARIO ARIEl GonzÁLEz PortA

PUC - SP

mariopor@pucsp.br

\section{Notas}

${ }^{1}$ Aceito aqui o que se pode considerar a posição clássica. Recentemente a mesma tem sido questionada por Rollinger (2002) e Betti (2013).

${ }^{2}$ Com respeito às abreviaturas utilizadas, veja- se bibliografia.

Principia 19(1): 49-63 (2015). 